\title{
Evaluation of Cognitive Distraction in a Real Vehicle Based on the Reflex Eye Movement
}

\author{
Le Anh Son ${ }^{1)}$ Tatsuya Suzuki ${ }^{2)}$ Hirofumi Aoki ${ }^{1)}$ \\ 1) Institute of Innovation for Future Society, Nagoya University \\ Furo-cho, Chikusa-ku, Nagoya, 464-8601,Japan (E-mail: leanhsonvn@gmail.com) (hiro.aoki@nagoya-u.jp) \\ 2) Graduate School of Engineering, Nagoya University \\ Furo-cho, Chikusa-ku, Nagoya, 464-8603, Japan (E-mail: t suzuki@nuem.nagoya-u.ac.jp)
}

Received on June 21, 2017

\begin{abstract}
We have developed a method to estimate driver distraction by mean of involuntary eye movement of the vestibulo-ocular reflex (VOR) and optokinetic response (OKR) by using a driving simulator. This paper presents a practical application of the method to the real vehicle situation. The main concern was whether we can measure the eye movement of VOR and OKR caused by the road surface vibration in the situation. The experiments were conducted with participants sitting on the passenger seat for safety reasons. The results have shown that our method can be applied for evaluating cognitive distraction not only in a driving simulator but also in actual vehicles.
\end{abstract}

KEY WORDS: Safety, Driver distraction, Vestibulo-ocular reflex (VOR), Optokinetic reflex (OKR) [C1]

\section{INTRODUCTION}

Driver distraction is one of the big problems in traffic safety. According to a report, driver distraction causes 8 fatalities and 778 injuries in the United States every day ${ }^{(1)}$. Cognitive distraction, where the driver is taken their mind off from driving ${ }^{(2)}$, is one of the most difficult situations to detect while driving. In the past, several researchers have proposed methods for capturing cognitive distraction. For example, the effect of workload was associated with pupil diameter by several researchers ${ }^{(3)(4)(5)(6)(7)}$. However, due to the lower sensitivity of the pupil size to light condition, this method easily fails to detect distraction in situations where the light changes markedly ${ }^{(8)}$. On the other hand, some researchers have suggested that the cognitive distraction has a strong influence on the blink duration ${ }^{(9)(10)}$. Inversely, Veltman and Gailard showed that there is no relationship between eye blink and cognitive workload when the operator has to process a significant amount of visual information ${ }^{(11)}$.

On the other hand, Obinata and his colleagues proposed a new method for online evaluation of driver distraction by using involuntary eye movement ${ }^{(12)(13)(14)(15)}$. In this method, the eye movement was simulated on the basis of the head movement using a vestibulo-ocular reflex (VOR) model. The difference between simulated and actual eye movement was used to evaluate the level of cognitive distraction. However, the model needs to be improved to apply for realistic driving situation assuming gaze changes and other environmental effects.

Son et al have developed a model that combines VOR model with optokinetic (OKR) model to simulate eye movement with changing gaze in a driving simulator ${ }^{(16)(17)(18)(19)(20)}$. In this paper, we applied the model to simulate eye movement to validate it for evaluating cognitive distraction in the actual vehicle.

\section{METHOD}

\subsection{Mathematical model for eye movement simulation}

The vestibular system, which is responsible for the maintenance of body balance, is the sensory system that provides the leading contributions to body movements: gaze stabilization, spatial navigation, spatial perception, and so on. As determined by previous researchers, the eye movement can be simulated base on the head movement by using VOR plus OKR model ${ }^{(21)(22)(23)}$.

\section{- VOR model}

The vestibulo-ocular reflex is one of the reflex eye movements. The eye movement was simulated as the function of angular velocity and the linear acceleration of the head. This 
model has been proposed by several researchers and applied to various applications.

We have adopted the model proposed by Merfeld and Zupan ${ }^{(21)}$ to deal with the interaction between the otoliths and the semicircular canals for this research.

Figure 1 shows the detail of the VOR model. The final common path segment proposed by Robinson is combined to simulate eye muscle. The model now contains four parameters to compensate for individual differences in VOR characteristics and two parameters to compensate for individual differences in eye muscle.

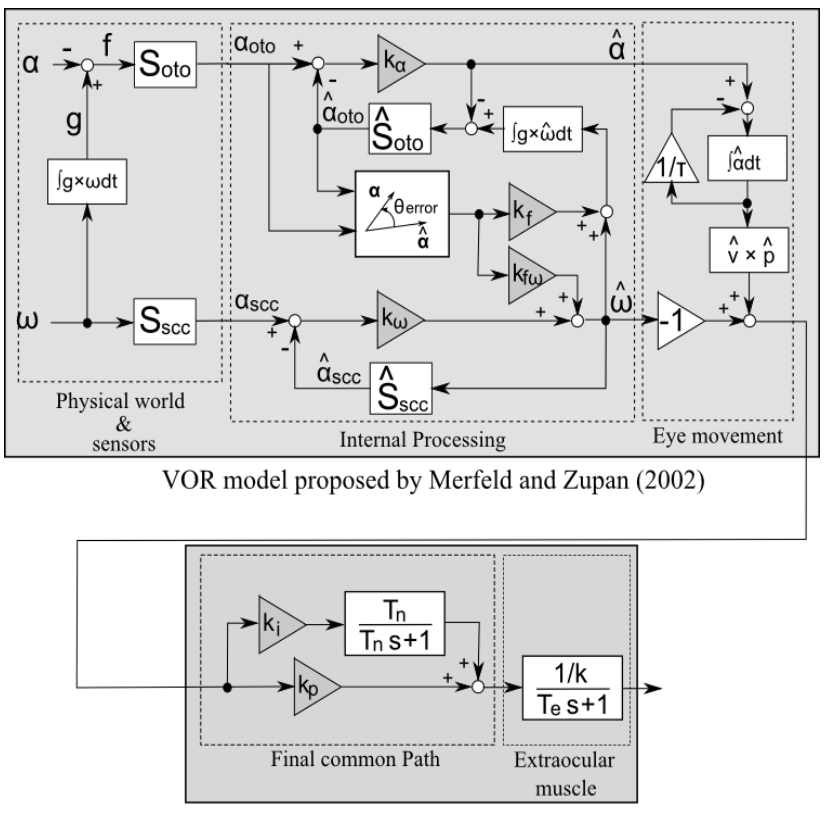

Final Common path part proposed by Robinson (1981)

Fig.1. VOR models developed by Obinata et al. (12)-(15)

The main idea to create four parameters is to minimize the sensory conflict error (Merfeld et al. 1993). In this model, the input of VOR model is the angular velocity $(\omega)$ and acceleration $(\alpha)$ of the head movement. The parameter $\mathrm{k}_{\alpha}$, which is linear acceleration feedback gain, feeds the acceleration back to the central estimator comparing the differences between actual and expected otolith signals. The parameter $\mathrm{k}_{\mathrm{f}}$, which is GIF feedback, scales the GIF rotation error to feed it back to the central estimator for the direction of gravity. It means that it weighted the difference between the direction of actual and expected otolith cues, while the remaining feedback gain $\left(\mathrm{k}_{\mathrm{f} \omega}\right)$ is weighted the rotation of the gravireceptor cues and used to adjust the observer's estimation of angular velocity. In other mission, the parameter $\mathrm{k}_{\omega}$ is angular velocity feedback gain, which corresponded to the slow phase velocity of VOR. On the other hand, four parameters $\left(k_{i h}, k_{i v}, k_{p h}\right.$, and $\mathrm{k}_{\mathrm{pv}}$ ) are contained in final common path part proposed by
Robinson (1981) to indicate the different type of muscle fibers present in the muscle of the eye.

As for drivers' behavior, this model has been previously used by several researchers to examine the relationship between drivers' states with eye movements. For example, Obinata's group has also used the VOR model to estimate the mental workload (MW) ${ }^{(14)}$ and driver distraction in terms of memory-decision workload ${ }^{(13)}$. They presented a new method for quantifying mental workloads by utilizing the VOR. However, they did not consider about changes in gaze direction. Omura et al. used the VOR model to determine the relationship between measured eye movements and subjective evaluations of simulated brake motion ${ }^{(24)}$. In their research, the passenger's comfort was measured by comparing the observed eye movement with its simulation on the basis of the VOR model. The researchers found a tendency of the relationship, but the number of the subjects was insufficient for ensuring decision.

\section{- Optokinetic model}

The vestibule-ocular reflex (VOR) is a reflex action that inertial stabilizes vision by producing eye movement toward the direction against head movement. On the other hand, the optokinetic response stabilizes image movement on one's retina. Hence, on a visual scene, the combination of VOR and OKR model is necessary to keep the eye stabilized in space and the visual scene ${ }^{(22)(25)}$. To do that, we applied the same technique with Son et al. ${ }^{(17)(19)}$ by including static and dynamic visual sensory information.

The process of visual input is shown in Figure 2.

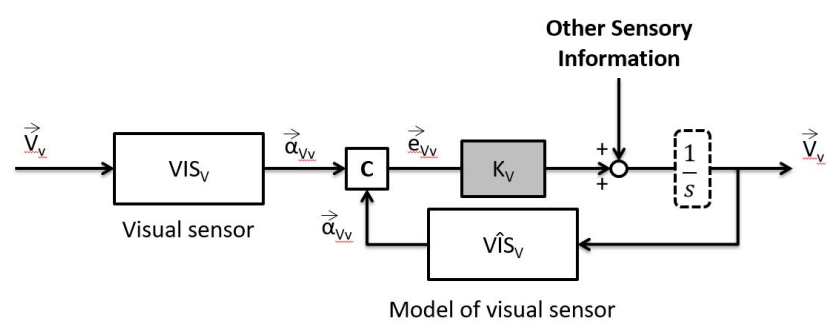

Fig.2. Generic visual model path way proposed by Newman

In a similar way with Newman, Clark, and Oman ${ }^{(26)}$, and the development of Son et al. ${ }^{(17)(18)}$, the combination of the VOR and OKR was made by one negative feedback loop. Details of the model are shown in Figure 3. The simulation model is divided into 3 parts: VOR, OKR, and final common path part. The primary input of VOR part is the angular velocity $(\omega)$ and acceleration $(\alpha)$ of the head movement. Besides that, the visual angular velocity $\left(\omega_{\mathrm{V}}\right)$ is an input for the OKR model. After the data processing, the output of the VOR and the OKR are the angular velocity of the eyeball in three directions. Due to the eventual angle of the eyeball, 
which defines the gaze direction, the integration of the angular velocity is done through the final common path, and extraocular muscle ${ }^{(21)}$.

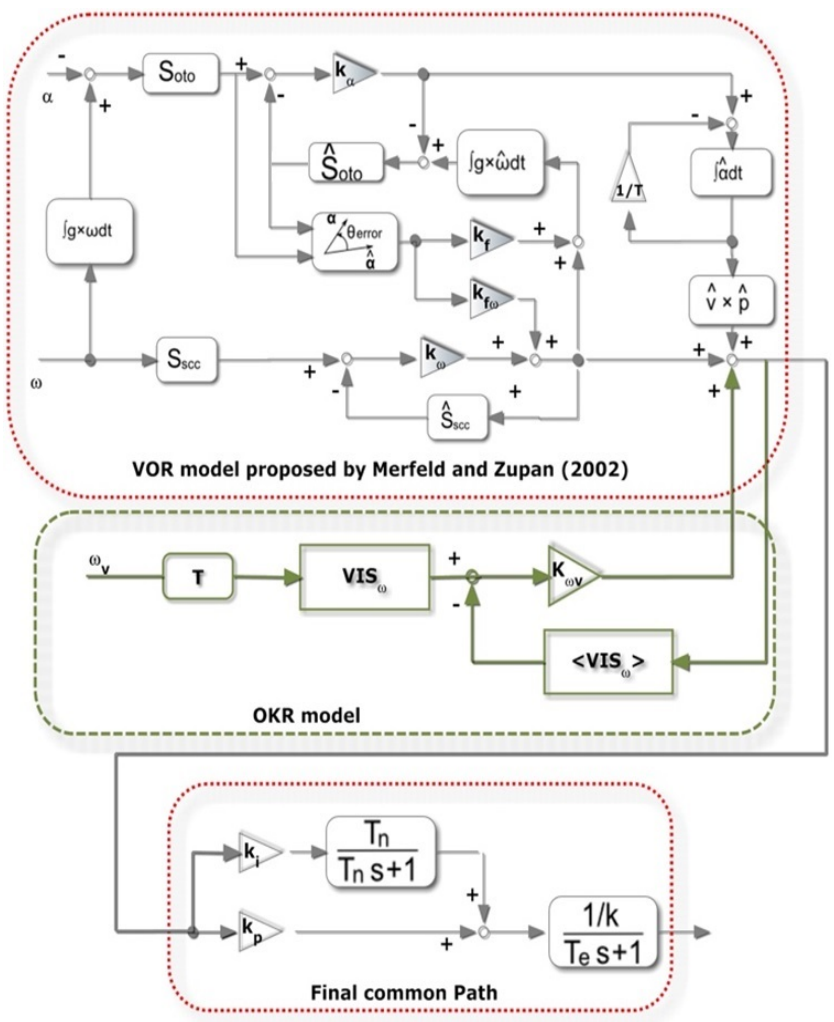

Fig.3. VOR + OKR model developed in this study

In this model, the visual input was calculated from head movement. Then it is processed by the visual sensor (VIS) to generate visual sensory estimation. This estimation is compared to an expected visual sensory evaluated from the internal model of the visual sensor $(<\mathrm{VIS}>)$. The difference between the visual sensory estimation and internal model of the visual sensor is weighted with a residual weighting parameter $\left(\mathrm{K}_{\omega \mathrm{V}}\right)$ and added to the rate of change of estimated state.

As the summary, the current model includes 4 parameters of the VOR model $\left(\mathrm{k}_{\alpha}\right.$ : the linear acceleration feedback gain, $\mathrm{k}_{\mathrm{f}}$ : the GIF feedback, $\mathrm{k}_{\mathrm{f} \omega}$ : the remaining feedback gain, $\mathrm{k}_{\omega}$ : the angular velocity feedback gain), one parameter from OKR model $\left(\mathrm{K}_{\omega \mathrm{V}}\right.$ : the residual weighting parameter), and 4 parameters from the final common path ( $\mathrm{k}_{\mathrm{ih}}, \mathrm{k}_{\mathrm{iv}}, \mathrm{k}_{\mathrm{ph}}$, and $\mathrm{k}_{\mathrm{pv}}$ ). In this study, the parameter of OKR was kept as a constant for all subjects as Newman (2009). On the other hand, the parameters of the VOR and the final common path was identified by the parameter identification method proposed by Son et al. ${ }^{(16)}$. This model was tested and validated with the real situation of an actual vehicle.

\subsection{Experimental setup}

The experiments were approved by the Nagoya University's Institute of Innovation for Future Society Ethical Review Board. All subjects were provided with explanations regarding the experimental procedure and gave their written informed consent.

In this experiment, the data from 13 subjects were collected. For the safety reason, a participant was asked to sit on the passenger seat. The driver drove the car in a private closed course 4 times: two times at $15 \mathrm{~km} / \mathrm{h}$ and two times at $30 \mathrm{~km} / \mathrm{h}$ (Table 1).

Table 1. Experiment condition

\begin{tabular}{|c|c|c|c|}
\hline & \multicolumn{2}{|c|}{ Mental Workload } \\
\hline & & Without & With \\
\hline \multirow{2}{*}{$\begin{array}{l}\text { Vehicle's } \\
\text { Velocity }\end{array}$} & $15 \mathrm{~km} / \mathrm{h}$ & Condition 1 & Condition 2 \\
\hline & $30 \mathrm{~km} / \mathrm{h}$ & Condition 3 & Condition 4 \\
\hline
\end{tabular}

At each condition of the speed, the participant was asked to relax for the first time and to answer the n-back task in the second times. The participants wore EyeSeeCam (EyeSeeTec GmbH) to capture the eye and head movement (Figure 4).

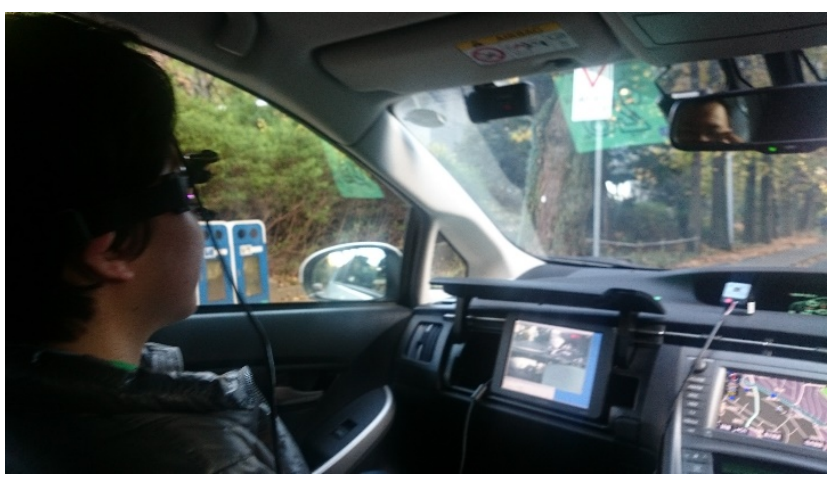

Fig.4. Experiment setup

The EyeSeeCam is the eye tracker by cameras using infrared reflecting hot mirrors. In this experiment, the raw head and eye measurement were captured by EyeSeeCam and it was filtered for the analysis.

In this research, we used a round trip straight route on a private road. During the experiment, there was sometimes other traffic such as a pedestrian, bicycle, motorbike, and car.

\section{- $\quad$ N-back task}

To impose a mental workload during driving, a n-back task of digit recall was used (Figure 5). In our n-back task, one number was verbally presented to the subject every one second. The subjects were asked to press the "Yes" when the number that appears was the same as the previous ones and the "No" button when it was different. 


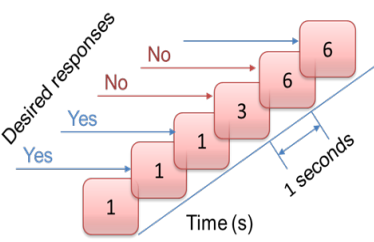

Fig.5. N-back task

\section{RESULTS AND DISCUSSIONS}

The data of the first 10 seconds, when the driver drove without a mental workload, was used to identify parameters using parameter identification toolbox that proposed by Son et al (16). These parameters were applied in both cases: with/without an nback task at the same speed with VOR+OKR model.

To deal with the difference of vibration, the levels of distraction were calculated by the normalized root mean square deviation (NRMSD), which is the difference between the model simulation and the actual eye movements (Equation. 1).

$$
N R M S D=\frac{\sqrt{\frac{\sum_{i=1}^{n}\left(\hat{y}_{i}-y_{i}\right)^{2}}{n}}}{y_{\max }-y_{\min }}
$$

Where n: Sample

$\hat{\mathrm{y}}_{\mathrm{i}}$ : Eye simulation value for observation $\mathrm{i}$

$\mathrm{y}_{\mathrm{i}}$ : Actual eye movement value for observation $\mathrm{i}$

\subsection{Parameter identification}

The speed plays a very important role in vehicle's vibration. Therefore, for one subject, we identified the parameter two times at $15 \mathrm{~km} / \mathrm{h}$ and $30 \mathrm{~km} / \mathrm{h}$ by using 10 seconds of without mental workload (Figure 6).

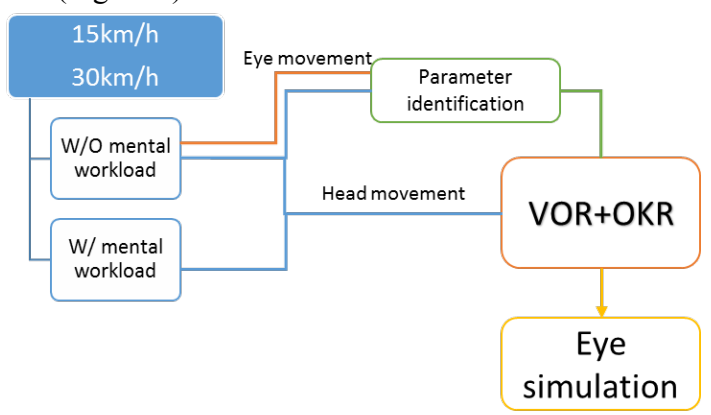

Fig.6. The data processing

After identifying parameter, it was applied to simulate eye movement by using the VOR+OKR model. In this model, the head velocity and acceleration were used as the input. The eye simulation shows good matching with low normalized root mean square deviation (NRMSD) in the case of without mental workload (Figure 7).

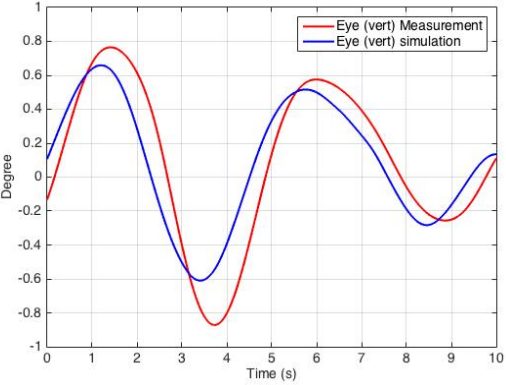

Fig.7. Parameter identification for subject 13

Furthermore, Figure 8 confirmed that the model worked well even in an actual environment with the random vibration from the vehicle.

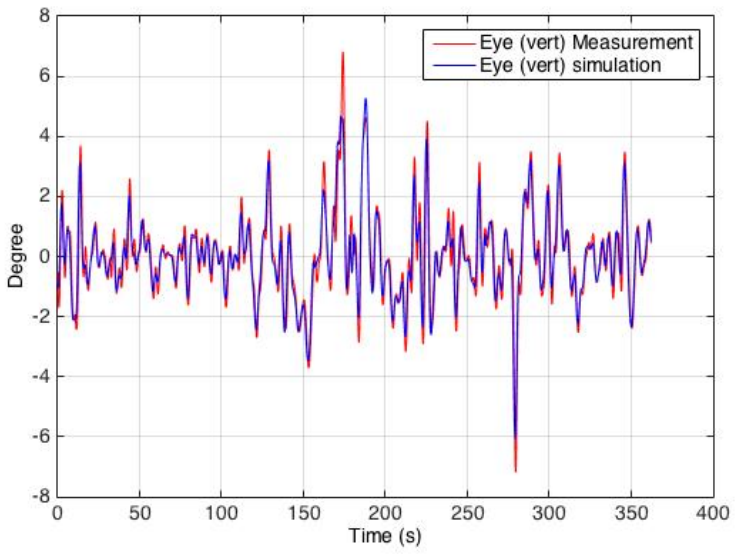

Fig.8. Eye Simulation for subject 13 (W/O mental workload at $15 \mathrm{~km} / \mathrm{h})$

\subsection{Effect of speed on eye movement simulation}

The vehicle's velocity has a strong impact on its vibration. The vibration of the vehicle depends on a lot of elements such as road condition, shock absorber, vehicle weight, and so on. In this research, the speed effected on the vibration that is the main cause of head movement. Therefore, due to the difference of speed, the actual head movement and the eye movement was different.

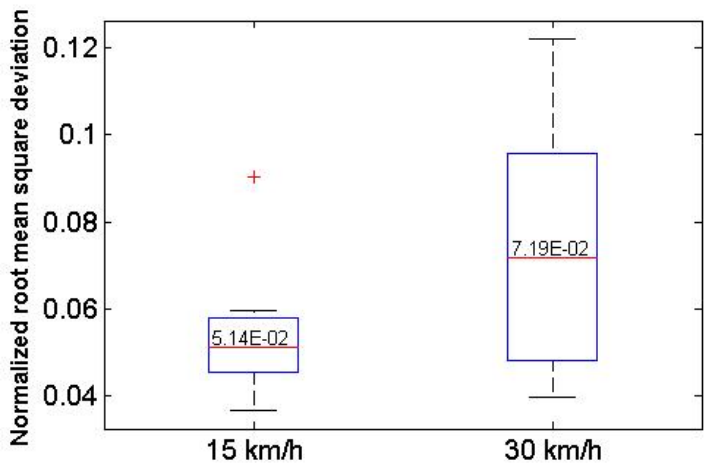

Fig.9. Normalized root mean square deviation (at $15 \mathrm{~km} / \mathrm{h}$ and 30 $\mathrm{km} / \mathrm{h})$

As shown in Figure 9 at higher speed, the NRMSD increased. Inversely, when the driver drove slower, the NRMSD decreases 
(at $15 \mathrm{~km} / \mathrm{h}$, NRMSD equal $5.14 \mathrm{E}-02$, at $30 \mathrm{~km} / \mathrm{h}$, NRMSD equal 7.19E-02).

The increasing of NRMSD may be caused by the difference of vibration while driving. As shown in figure 10, the eye movement at $30 \mathrm{~km} / \mathrm{h}$ has a larger difference than $15 \mathrm{~km} / \mathrm{h}$ (figure 8 ).

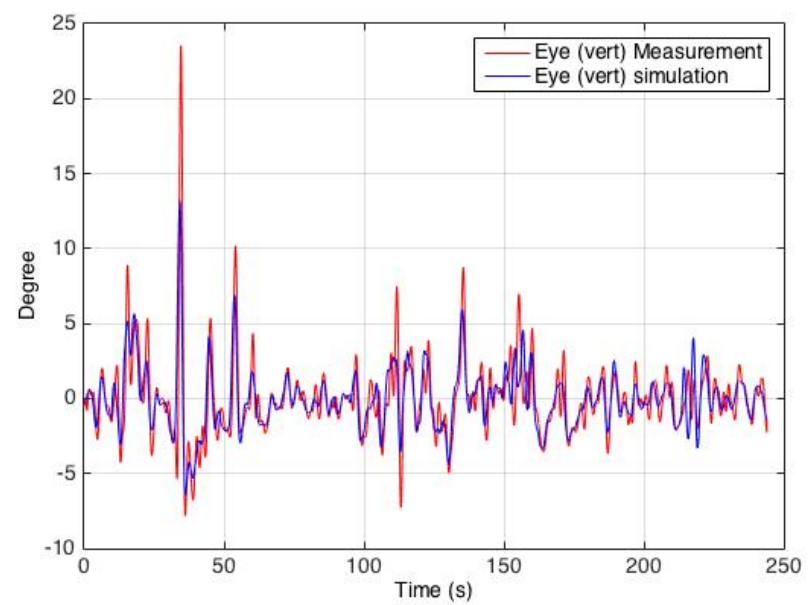

Fig.10. Eye Simulation for subject 13 (W/O mental workload at $30 \mathrm{~km} / \mathrm{h}$ )

\subsection{Effect of mental workload on eye movement}

Based on the data analysis, the results shown the NRMSD between the simulated and observed eye movement became larger in the presence of mental workload. The median of NRMSD in the case of without MW is 5.74E-02, and it increases to 7.33E-02 in the case of with MW (Figure 11). Table 2 shows more detail of NRMSD of each subject in the experiment.

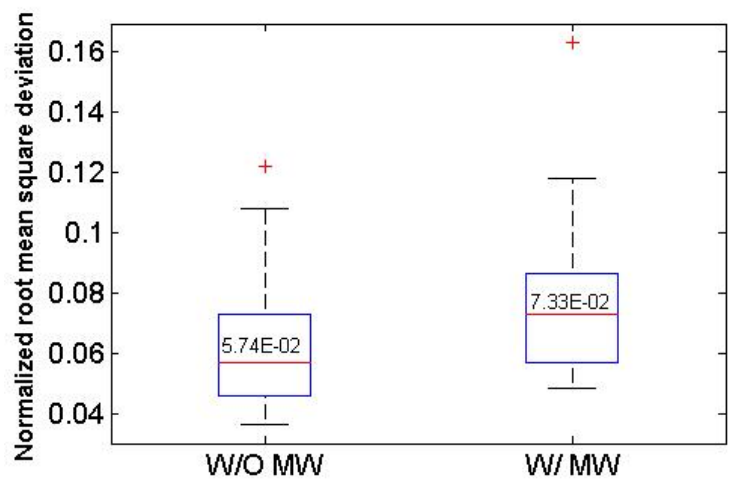

Fig. 11. Normalized root mean square deviation $(\mathrm{W} /$ and $\mathrm{W} / \mathrm{O}$ MW)

All 13 subjects show a similar trend with the increasing of NRMSD with MW. This confirms that this method can detect driver cognitive distraction with respect to the difference between simulation and measurement of eye movement in actual condition.
Table 2: NRMSD of each subject

\begin{tabular}{|l|l|l|l|l|l|l|}
\hline & \multicolumn{3}{|c|}{$15 \mathrm{~km} / \mathbf{h}$} & \multicolumn{3}{c|}{$30 \mathrm{~km} / \mathbf{h}$} \\
\cline { 2 - 8 } & W/O MW & W/ MW & Ratio & W/O MW & W/ MW & Ratio \\
\hline S1 & $4.43 \mathrm{E}-02$ & $4.94 \mathrm{E}-02$ & 1.12 & $4.52 \mathrm{E}-02$ & $4.87 \mathrm{E}-02$ & 1.08 \\
\hline S2 & $5.96 \mathrm{E}-02$ & $7.29 \mathrm{E}-02$ & 1.22 & $7.31 \mathrm{E}-02$ & $7.72 \mathrm{E}-02$ & 1.06 \\
\hline S3 & $4.72 \mathrm{E}-02$ & $6.63 \mathrm{E}-02$ & 1.40 & $4.91 \mathrm{E}-02$ & $7.97 \mathrm{E}-02$ & 1.62 \\
\hline S4 & $9.02 \mathrm{E}-02$ & $1.01 \mathrm{E}-01$ & 1.12 & $1.08 \mathrm{E}-01$ & $1.11 \mathrm{E}-01$ & 1.03 \\
\hline S5 & $4.79 \mathrm{E}-02$ & $5.12 \mathrm{E}-02$ & 1.07 & $9.66 \mathrm{E}-02$ & $1.05 \mathrm{E}-01$ & 1.09 \\
\hline S6 & $5.14 \mathrm{E}-02$ & $5.17 \mathrm{E}-02$ & 1.01 & $6.08 \mathrm{E}-02$ & $6.36 \mathrm{E}-02$ & 1.05 \\
\hline S7 & $5.29 \mathrm{E}-02$ & $7.37 \mathrm{E}-02$ & 1.39 & $7.66 \mathrm{E}-02$ & $8.01 \mathrm{E}-02$ & 1.05 \\
\hline S8 & $5.76 \mathrm{E}-02$ & $6.28 \mathrm{E}-02$ & 1.09 & $9.55 \mathrm{E}-02$ & $1.18 \mathrm{E}-01$ & 1.23 \\
\hline S9 & $5.72 \mathrm{E}-02$ & $6.88 \mathrm{E}-02$ & 1.20 & $1.22 \mathrm{E}-01$ & $1.63 \mathrm{E}-01$ & 1.33 \\
\hline S10 & $3.68 \mathrm{E}-02$ & $5.70 \mathrm{E}-02$ & 1.55 & $4.51 \mathrm{E}-02$ & $7.68 \mathrm{E}-02$ & 1.70 \\
\hline S11 & $3.91 \mathrm{E}-02$ & $5.54 \mathrm{E}-02$ & 1.42 & $3.99 \mathrm{E}-02$ & $5.02 \mathrm{E}-02$ & 1.26 \\
\hline S12 & $4.60 \mathrm{E}-02$ & $6.11 \mathrm{E}-02$ & 1.33 & $7.19 \mathrm{E}-02$ & $8.69 \mathrm{E}-02$ & 1.21 \\
\hline S13 & $5.96 \mathrm{E}-02$ & $8.15 \mathrm{E}-02$ & 1.37 & $6.96 \mathrm{E}-02$ & $9.48 \mathrm{E}-02$ & 1.36 \\
\hline
\end{tabular}

To look deeply into the difference in the case of with and without a mental workload, the eye simulation and eye measurement in both cases were shown in Figure 12 and Figure 13.

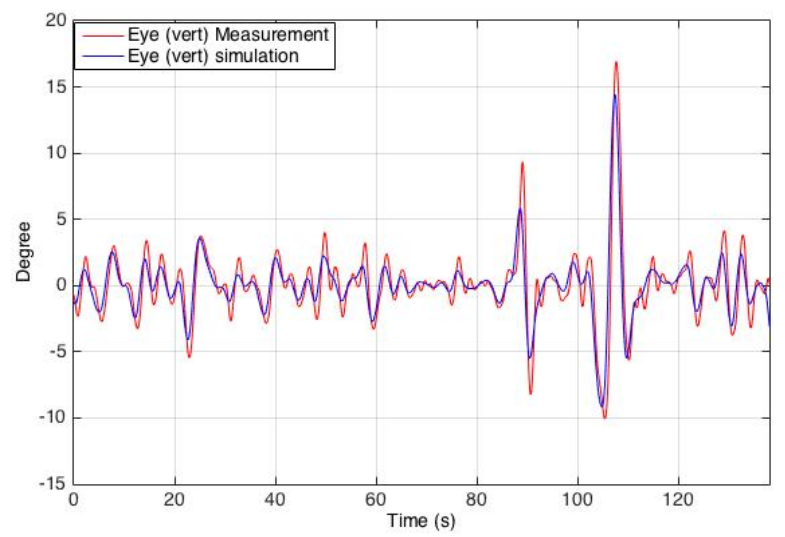

Fig.12. Subject $3-$ Without MW at $15 \mathrm{~km} / \mathrm{h}$

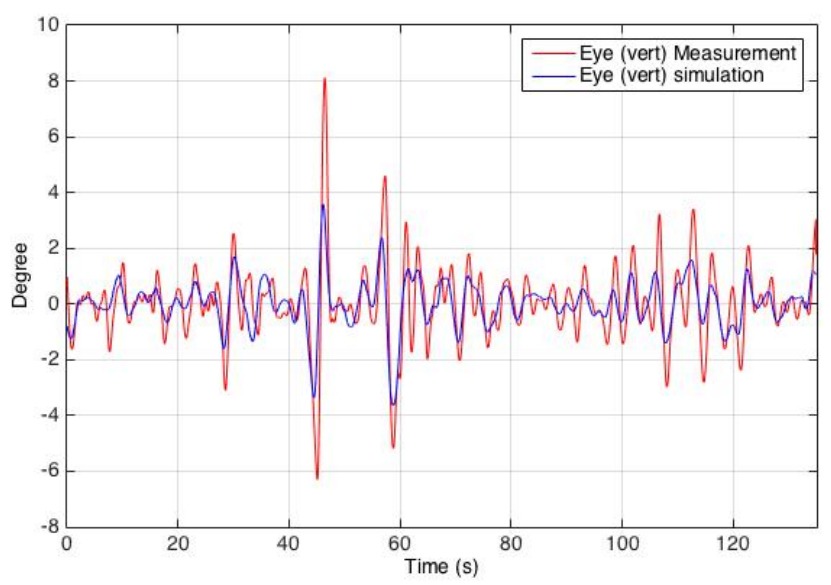

Fig.13. Subject 3 - With MW at $15 \mathrm{~km} / \mathrm{h}$ 
The results once again confirmed that, in the present of the nback task, the eye movement simulation became miss matching in both time response and magnitude response.

\subsection{ANOVA analysis}

Furthermore, an ANOVA analysis was made with the main purpose to see the effect of speed and mental workload on driver distraction. The result will be shown in table 3 .

Table 3. ANOVA results

\begin{tabular}{|l|r|r|r|r|l|}
\hline & Df & \multicolumn{1}{|c|}{ Sum Sq } & \multicolumn{1}{c|}{ Mean Sq } & $\begin{array}{c}\text { v } \\
\text { value }\end{array}$ & $\operatorname{Pr}(>\mathrm{F})$ \\
\hline Speed & 1 & $6.16 \mathrm{E}-03$ & $6.16 \mathrm{E}-03$ & 12.52 & $8.91 \mathrm{E}-04 * * *$ \\
\hline MW & 1 & $2.56 \mathrm{E}-03$ & $2.56 \mathrm{E}-03$ & 5.2 & $2.70 \mathrm{E}-02 *$ \\
\hline SP:MW & 1 & $2.90 \mathrm{E}-05$ & $2.90 \mathrm{E}-05$ & 0.06 & 0.81 \\
\hline Residuals & 48 & $2.41 \mathrm{E}-02$ & $5.01 \mathrm{E}-04$ & & \\
\hline--- & & & & \\
\hline \multicolumn{7}{|c|}{ Signif. codes: ‘***': $<<0.001 \quad$ '*': $<<0.05$} \\
\hline
\end{tabular}

Like the previous results, ANOVA for the model once again shows a significant effect $(\mathrm{F}=5.2, \mathrm{p}<0.05)$, it confirms that this method can detect mental workload while driving by comparing the eye simulated and predicted.

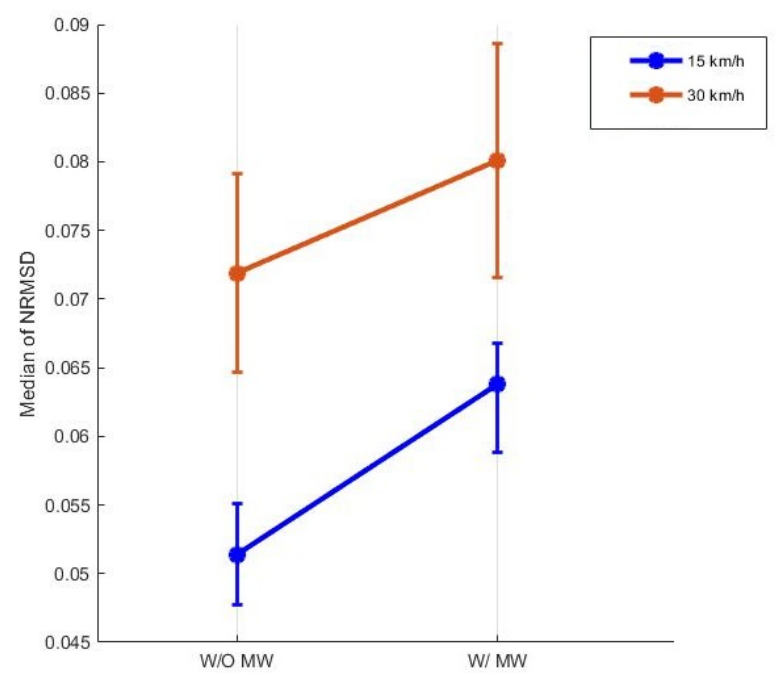

Fig. 14. NRMSD

On the other hand, in the case of $15 \mathrm{~km} / \mathrm{h}$, the NRMSD increased from $5.14 \mathrm{E}-02$ to $6.28 \mathrm{E}-02$. In the same trend, the NRMSD was growing up from 7.19E-02 to 8.01E-02 in the case of $30 \mathrm{~km} / \mathrm{h}$. In addition, in ANOVA results, the interaction between speed and mental workload was not significant. It means that the relationship between mental workload and driver distraction do not depend on speed. Furthermore, the ANOVA results also indicated that the velocity of the vehicle has a strong effect on the difference of eye measurement and simulation.
Vehicle's vibration is one of the reasons of the difference, i.e., the error, as well as the main effect for generating the vestibulo-ocular reflex. Although the OKR model was eliminated the effect of optic flow cause by visual scanning characteristics on eye simulation, the small error may still remain and increase along with the increase of the speed. We assume that the main reason for the increasing error while changing the speed would be the driver cognitive load. Basically, the cognitive load depends on the visual information, and when it increases the functionality of the brain was reduced. It makes the internal part in VOR model become abnormal. Therefore the error between the eye simulation and eye measurement become larger. In the future, further research to separate the effect of the road surface, optic flow, and the cognitive load by vehicle speed should be conducted.

\section{CONCLUSION}

The model that consists of both VOR and OKR can indicate the driver distraction while driving by comparing the eye simulation and eye measurement.

On the other hand, due to the limitation of speed condition, the effect of speed on the eye simulation model was not so clear. In near future, we will try to collect more data by changing the speed condition and road condition to clearly see the effect of them on the model.

This paper is written based on a proceeding presented at JSAE 2017 Spring Annual Congress.

\section{ACKNOWLEDGMENT}

This research is in part supported by Toyota Motor Corporation. We want to send special thanks to Professor Kiyohisa Nishiyama, Doctor Makoto Inagami - Nagoya University, Hiroto Hamada Toyota Company for giving us the valuable comments and so on.

\section{REFERENCES}

(1) NHTSA, "Research Note Distracted Driving 2013," Dot Hs 812 132, No. April 2015, pp. 1-8, (2015).

(2) National Highway Traffic Safety Administration, "National Motor Vehicle Crash Causation Survey Report to Congress," No. July, pp. 1-47, (2008).

(3) R. W. Backs and L. C. Walratht, "Eye movement and pupillary response indices of mental workload during a visual search of symbolic displays," Applied Ergonomic., Vol. 23, No. 4, pp. 243-254, (1992).

(4) S. T. Iqbal, X. S. Zheng, and B. P. Bailey, "Task-evoked pupillary response to mental workload in human-computer 
interaction," Extended abstracts of the 2004 conference on Human factors and computing systems CHI 04, p. 1477, (2004).

(5) J. Klingner, R. Kumar, and P. Hanrahan, "Measuring the task-evoked pupillary response with a remote eye tracker," Proceedings of the 2008 symposium on Eye tracking research \& applications - ETRA '08, Vol. 1, No. 212, p. 69, (2008).

(6) M. Schwalm, A. Keinath, and H. D. Zimmer, "Pupillometry as a method for measuring mental workload within a simulated driving task," Human Factors for assistance and automation, No. 1986, pp. 1-13, (2008).

(7) M. Niezgoda, A. Tarnowski, M. Kruszewski, and T. Kamiski, "Towards testing auditory-vocal interfaces and detecting distraction while driving: A comparison of eyemovement measures in the assessment of cognitive workload," Transportation Research Part F: Traffic Psychology and Behaviour., Vol. 32, pp. 23-34, (2015).

(8) O. Palinko and A. Kun, "Exploring the influence of light and cognitive load on pupil diameter in driving simulator studies," Proceedings of the Symposium on Eye Tracking Research and Applications., pp. 413-416, (2012).

(9) S. Benedetto, M. Pedrotti, L. Minin, T. Baccino, A. Re, and R. Montanari, "Driver workload and eye blink duration," Transportation Research Part F: Traffic Psychology and Behaviour., Vol. 14, No. 3, pp. 199-208, (2011).

(10) V. Faure, R. Lobjois, and N. Benguigui, "The effects of driving environment complexity and dual tasking on drivers' mental workload and eye blink behavior," Transportation Research Part F: Traffic Psychology and Behaviour., Vol. 40, pp. 78-90, (2016).

(11) J. A. Veltman and A. W. K. Gaillard, "Physiological indices of workload in a simulated flight task," Biological Psychology., Vol. 42, No. 3, pp. 323-342, (1996).

(12) T. Usui, G. Obinata, and N. Shibata, "On-line method for evaluating the driver distractions of memory-decision work load based on dynamics of vestibulo-ocular reflex," Proceedings of International Symposium on EcoTopia Science., Vol. 7, pp. 1132-1136, (2007).

(13) G. Obinata, T. Usui, and N. Shibata, "On-line Method for Evaluating Driver Distraction of Memory-decision Workload Based on Dynamics of Vestibulo-ocular Reflex,"
Review of Automotive Engineering., Vol. 29, No. 4, pp. 627-632, (2008).

(14) G. Obinata, S. Tokuda, K. Fukuda, and H. Hamada, "Quantitative Evaluation of Mental Workload by Using Model of Involuntary Eye Movement," in Engineering Psychology and Cognitive Ergonomics SE - 24, Vol. 5639, D. Harris, Ed. Springer Berlin Heidelberg, pp. 223-232, (2009).

(15) G. Obinata, K. Fukuda, A. Moriyama, S. Tokuda, and Y. W. Kim, "Evaluating the influence of distractions to drivers based on reflex eye movement model," IFAC Proceedings Volumes (IFAC-PapersOnline), Vol. 11, No. PART 1. IFAC, (2010).

(16) L. Anh Son, H. Aoki, H. Hamada, and T. Suzuki, "Parameters Optimization Using Genetic Algorithm Technique for Vestibulo-ocular Reflex model," Future Active Safety Technology Towards zero traffic accidents, (2015).

(17) L. Anh Son, M. Inagami, H. Hamada, T. Suzuki, and H. Aoki, "The Effect of Visual Stimulus on the Mental Workload Estimation Based on a VOR/OKR Model," International Journal of Automotive Engineering., Vol 8, No. 2, pp. 37-44, (2017).

(18) H. Aoki, L. Anh Son, H. Hamada, T. Suzuki, and G. Obinata, "Quantitative Evaluation of Mental Workload with Voluntary Eye Movements by Means of the VestibuloOcular Reflex," Proceedings of 2015 Japan Society Automotive Engineering Annual Congress., pp. 780-785, (2015).

(19) L. Anh Son, H. Hamada, M. Inagami, T. Suzuki, and H. Aoki, "Effect of Mental Workload and Aging on Driver Distraction Based on the Involuntary Eye Movement," in Advances in Human Aspects of Transportation: Proceedings of the AHFE 2016 International Conference on Human Factors in Transportation, July 27-31, 2016, Walt Disney World ${ }^{\circledR}$, Florida, USA, A. N. Stanton, S. Landry, G. Di Bucchianico, and A. Vallicelli, Eds. Cham: Springer International Publishing, pp. 349-359, (2016).

(20) L. Anh Son, H. Aoki, and T. Suzuki, "Evaluation of Driver Distraction with Changes in Gaze Direction Based on a Vestibulo-Ocular Reflex Model," Journal of Transportation Technologies., Vol 7, pp. 336-350, (2017). 
(21) D. M. Merfeld, L. H. Zupan, J. Vestibular, M. Eye, and E. Infirmary, "Neural Processing of Gravitoinertial Cues in Humans. III . Modeling Tilt and Translation Responses," Journal of neurophysiology, pp. 819-833, (2002).

(22) D. A. Robinson, "The use of control systems analysis in the neurophysiology of eye movements," Annual review of neuroscience, Vol. 4, pp. 463-503, (1981).

(23) L. H. Zupan and D. M. Merfeld, "Neural processing of gravito-inertial cues in humans. IV. Influence of visual rotational cues during roll optokinetic stimuli." Journal of neurophysiology., Vol. 89, pp. 390-400, (2003).

(24) K. Omura, H. Aoki, and G. Obinata, "Objective evaluation of the brake motion by means of passenger's reflex eye movements," International symposium on Future active safety teachnology, Vol. 13, (2014).

(25) G. Schweigart, T. Mergner, I. Evdokimidis, S. Morand, and W. Becker, "Gaze stabilization by optokinetic reflex (OKR) and vestibule-ocular reflex (VOR) during active head rotation in man," Vision Research., Vol. 37, No. 12, pp. 1643-1652, (1997).

(26) T. K. Clark, M. C. Newman, C. M. Oman, D. M. Merfeld, and L. R. Young, "Human perceptual overestimation of whole body roll tilt in hypergravity.," Journal Neurophysiology, Vol. 113, No. 7, pp. 2062-2077, (2015). 